Article

\title{
Cross-cultural adaptation and reliability of the Back Pain and Body Posture Evaluation Instrument (BackPEI) for Spanish
}

\author{
Vicente Miñana-Signes ${ }^{1, *}$, Manuel Monfort-Pañego ${ }^{1}$, Joan Morant ${ }^{2}$ and Matias Noll ${ }^{3}$ \\ 1 Body Languages Didactics Department. Academic Unit of Physical Education. Teacher Training Faculty. \\ University of Valencia. Av. dels Tarongers, 4, 46022, Valencia. Spain; \\ 2 Postgraduate student of the Teacher Training Faculty of the University of Valencia; \\ 3 Instituto Federal Goiano, Physical Education, rua 17, qd 53, lt 10A, Bairro Centro, Rialma, Goias, Brazil \\ * Correspondence: V. Miñana. E-mail: vicente.minana@uv.es
}

\begin{abstract}
The prevalence of back pain (BP) among children and adolescents has been increasing in the last years. Some authors advocate to promote the back health education in the school setting. It should be important to adopt a uniform suite of assessment instruments to measure the various constructs. The present study aimed to translate and validate a Spanish-language adaptation of the Back Pain and Body Posture Evaluation Instrument (BackPEI) for adolescents. The translation and cross-cultural adaptation were performed according to the recommendations of guidelines. Reliability was tested by applying the questionnaire to 224 secondary students, at two different times with a 7-day interval. In general, the Spanish version presented adequate agreement for questions $1-20$. The question about the pain intensity did not show differences between the averages for the test $(X=4.72 \pm S D=2.33)$ and re-test $(X=4.58 \pm S D=2.37)(p=.333)$, and the responses for these two tests were highly correlated (ICC $=.951,95 \%$ IC: .928- .966; $\mathrm{p}=.0001)$. Psychometric testing indicated that the Spanish version of the BackPEI provided valid and reliable scores that were similar to the results obtained with the original Brazilian version.
\end{abstract}

Keywords: Questionnaire, back health, assessment, cross-cultural adaptation, adolescents, secondary school.

\section{Introduction}

The prevalence of back pain (BP) among children and adolescents has been increasing in the last years $(1,2)$. These symptoms (3) are associated with a wide range of risk factors $(4,5)$ among which we highlight the sedentary positions caused by prolonged sitting in school days, as well as at home in front of computers or other IT devices, and the poor body use of students (6). On the other hand, it is known that, from the ages of 10 and 14, these episodes of discomfort begin to be experienced in a significant way (7-9), which may have repercussions in adulthood (10).

According this background, some authors and organizations advocate to promote the back health education research line and specially to implement school-based education programmes (1113). However, in order to reach robust conclusions about posture interventions in schools, it should be important to adopt a uniform suite of assessment instruments to measure the various contents in the investigations (BP prevalence, general and specific back care knowledge, daily postural habits, student's and teachers' perceptions...) (14).

To the best of our knowledge, there are only two validated and reliable self-reported evaluation instruments about postural habits with an educational orientation and content: the BackPEI questionnaire (Back Pain and Body Posture Evaluation Instrument) (15), and the BEHALVES questionnaire (Back-hEalthrelated postural Habits in dAiLy actiVitiES) (16). Furthermore, they have been validated in different cultures which makes its use useful only in those settings. 
In such circumstances, the adaptation and cross-cultural validation of the BackPEI could be the first step to consolidate valid instruments. Then, it could allow a criterion validity study to be carried out when comparing its instrumental behaviour against other questionnaires also validated such as BEHALVES (17). To obtain a good validation instrument research may take several years and it is normally conducted using more than one study to adhere to the recommended methodological approaches (18).

Therefore, the present study aimed to translate and validate a Spanish-language adaptation of the Back Pain and Body Posture Evaluation Instrument (BackPEI) for adolescents. And in this way, we intend to answer the research question that said, could we prepare a validated assessment tool to contribute to the improvement of back health? It was hypothesed that Spanish version of the BackPEI presents a degree of agreement similar to that of the original validated instrument.

\section{Materials and Methods}

\subsection{Study design}

A cross-cultural adaptation study based on a test-retest reliability design was performed.

\subsection{Translation and cross-cultural adaptation}

Translation and cross-cultural adaptation of the original Brazilian version of the BackPEI into a Spanish version was conducted according to the established guidelines $(18,19)$ and it was consisted of six steps. Every step was reviewed by the Authors of the Present study as Organizers and Mediators (APSOM) of the Delphi-process. The first five steps aimed to achieve equivalence between the instrument in the source language (SL; original language of the instrument, Portuguese) and the instrument in the and the target language (TL; desired language, Spanish).

First step: The forward translation (from SL to TL) was performed by a bilingual and native Brazilian researcher of the Teacher Training Faculty of the University of Valencia (UV).

Second step: The blind backward translation (from TL to SL) was developed by another independent, bilingual and native Brazilian researcher Polytechnic University of Valencia, who did not have knowledge of the original Brazilian text, and who produced a translation of the consensus target language version. The purpose of this step was to highlight discrepancies between the source document and the translation. However, there is currently no rigorous evidence of the value of the backward translation in questionnaire adaptation, leading to suggestions that it could be omitted (20).

Third step: Comparison of the target questionnaire with the original version (from SL to SL) contrasted by a researcher and professor of the UV. The objective in this step was to detect the possible differences between the backward translation and the original version and to improve these through consensus among translators.

Fourth step: Then, an Expert Committee composed by bilingual and professors of the "Instituto Federal Goiano" from Brazil and specialized in physical education, physiotherapy and public health reviewed the Spanish version (TL) compared with the original (SL). The objective of the committee was the production of a prefinal version for field testing, based on forward translation and backward translation obtained. The Delphi method was used. The anonymous responses were aggregated and shared with the group after each round. The experts were allowed to adjust their answers in subsequent rounds. Each committee member compared the Spanish version and original versions of the BackPEI on an item-by-item basis and in general (all items) by scoring the equivalence between the two versions through four questions in terms of semantic (i.e., equivalence in the meaning of words), idiomatic (i.e., equivalence in idioms and colloquialisms), experiential (i.e., equivalence in the target cultural context) and conceptual (i.e., equivalence of the concept and the experiences of the target culture) (Table 1).

Table 1 Assessment Instrument Questions for Experts.

Questions

1. Is the Spanish translation of the Portuguese version adequate? Observations 
2. Is the vocabulary used in the Spanish version of the questionnaire correct and understandable in relation to the Portuguese questionnaire? Observations

3. Is the style and registration of the questionnaire translated into Spanish faithful to the original Portuguese version? Observations

4. Do you consider that the questions asked fit into the culture of Portuguese / Brazilian speakers? Observations

The equivalence was scored using the surveys to collect experts' responses to 5-point Likert scales and making observations as an open-ended question. The five categories of the Likert scale were (1) Strongly Disagree; (2) Disagree; (3) Neither Agree nor Disagree; (4) Agree; (5) Strongly Agree) (21). The experts expressed their opinion by selecting only one category per statement. After the evaluation of each individual item, all items evaluated with modification were discussed and revised to produce the final Spanish version of the BackPEI. Since multiple rounds of questions were asked and the panel was told what the group thinks as a whole, the Delphi method sought to reach the correct response through consensus. This Dephi-process needed three rounds.

Fifth step: Any proofreading errors were corrected before the prefinal Spanish version of the BackPEI was produced.

Sixth step: Psychometric testing of the prefinal version of the translated instrument in a sample of the target population.

Participants

Once we had the prefinal version, we administrated the new questionnaire an adolescent population. A sample of 400 students from a secondary public school, chosen based on convenience factor, of the Valencian Community (Spain) consented to participate in the study. 176 participants were excluded because 1) they did not complete the second questionnaire, 2) they had a high number of omitted answers (more than $20 \%$ of the questions) and 3) because they forgot to put the control name in the written questionnaire. The final sample was 224 students ( $56 \%$ recruited; $15.1 \pm 1.4$ years old; $48.7 \%$ girls, $\mathrm{n}=109$ ) participated in this investigation (table 2 ). According to Sousa \& Rojjanasrirat (18) it is recommended to use at least 10 subjects per item of the instrument. BackPEI having 21 questions would require at least 210 participants.

Table 2 Descriptive data of the sample.

\begin{tabular}{ccccc}
\hline Age (years) & Gender & $\mathbf{n}$ & X Weight $(\mathbf{k g})( \pm \mathbf{S D})$ & X Height $(\mathbf{c m}) \mathbf{( \pm \mathbf { S D } )}$ \\
\hline \multirow{2}{*}{13} & $\mathrm{~F}$ & 11 & $42.7( \pm 7.2)$ & $1.54( \pm .05)$ \\
& $\mathrm{M}$ & 13 & $46.9( \pm 11.9)$ & $1.55( \pm .12)$ \\
14 & $\mathrm{~F}$ & 28 & $47.4( \pm 7.5)$ & $1.62( \pm .07)$ \\
& $\mathrm{M}$ & 26 & $55.9( \pm 12.6)$ & $1.66( \pm .08)$ \\
15 & $\mathrm{~F}$ & 31 & $52.5( \pm 8.1)$ & $1.64( \pm .06)$ \\
& $\mathrm{M}$ & 26 & $60.2( \pm 9.5)$ & $1.73( \pm .07)$ \\
16 & $\mathrm{~F}$ & 20 & $54.2( \pm 8.9)$ & $1.63( \pm .07)$ \\
& $\mathrm{M}$ & 14 & $66.6( \pm 11.7)$ & $1.74( \pm .08)$ \\
17 & $\mathrm{~F}$ & 17 & $54.0( \pm 5.3)$ & $1.62( \pm .08)$ \\
& $\mathrm{M}$ & 22 & $68.5( \pm 12.0)$ & $1.76( \pm .07)$ \\
18 & $\mathrm{~F}$ & 1 & 57.00 & 1.70 \\
& $\mathrm{M}$ & 5 & $73.0( \pm 6.7)$ & $1.77( \pm .07)$ \\
\hline
\end{tabular}

$\mathrm{F}=$ female; $\mathrm{M}=$ male; $\mathrm{X}=$ mean; $\mathrm{SD}=$ standard deviation.

\subsection{Evaluation Instrument}

The BackPEI questionnaire (15) is designed to identify the presence of BP in the 3 months prior to its application and includes questions on the occurrence, frequency and intensity of the pain. The intensity of the pain, question number 21, was assessed using the visual analog scale (VAS), which consists of a 10-cm horizontal line in which "0" means "No Pain" and " 10 " means "The Worst Pain 
I Can Imagine". Besides pain, this questionnaire also assesses risk factors associated with BP, such as: demographic, socio-economic, hereditary, and behavioural.

\subsection{Procedures}

\subsubsection{Ethical statements}

We obtained institutional ethical approval by the Ethics Committee in experimental research from the University of Valencia (reference number: H1529993833413). Besides, all students voluntarily participated in the study. The school principal and the parents were informed about the study and provided written informed consent.

\subsubsection{Data collection}

This study was carried out between July 2019 and February 2020. Data collection was undertaken during the second term of 2020 at school facilities under the supervision of one member of our research group in the presence of Physical Education teachers before the Severe Acute Respiratory Syndrome Coronavirus 2 (SARS-CoV-2). The written questionnaires to evaluate the testretest reliability were administered twice within a seven-day interval (22) during physical education classes. The student used an average of 10 and 20 minutes to complete the questionnaire according to age.

\subsection{Data analysis}

In the Delphi analysis, consensus on validating was achieved when at least $80 \%$ of the expert panel scored an item equal to four or higher $(4=$ Agree, $5=$ Strongly agree). It was analysed the expert's responses to the open-ended questions to identify, modify and include 1) semantic, idiomatic, experiential, and conceptual equivalences and 2) consider any comment related to the study.

Descriptive and inferential statistics were used in the study as proposed the authors (15). The data from the BackPEI test and re-test procedures for questions 1-20 were analysed using the unweighted Cohen's kappa coefficient ( $\mathrm{k}$ ) coefficient for nominal scales (unordered categories). The results were classified as poor $(\mathrm{k}<.2)$, fair $(.2 \backslash \mathrm{k}$ to .4$)$, moderate $(.4 \backslash \mathrm{k}$ to .6$)$, good $(.6 \backslash \mathrm{k}$ to .8$)$ or very good $(k>8)(23)$. For a question to remain included in the BackPEI, it was required to obtain a minimum value of $\mathrm{k}=.5(24)$. As it is an interval question, the agreement between the test and re-test of question 21 (pain intensity) was measured in terms of the relationship between the answers, as revealed using the intraclass correlation coefficients (ICC). The Wilcoxon test was used to compare the measures of central tendency obtained in the evaluations. The level of significance adopted was 0.05. Data analysis was performed using the SPSS $®$ IBM $®$ software, r. 26.

\section{Results}

\subsection{Translation and cross-cultural adaptation}

During the first step (forward translation) analysis, the APSOM decided not do any change. Step 2 (backward translation) was identical to the original questionnaire in Portuguese (SL). In the third step no major problems were encountered during the forward translation and backward translation phases of the Brazilian version, and the APSOM did not suggest amendments to words or phrases. Step 4 (Expert Committee): The committee used three rounds to accomplish the objective of the study, the production of a prefinal version for field testing. Each expert scored 88 items in the respective rounds.

In the first one, all items in general and item-by-item basis achieved $80 \%$ of the expert panel consensus. Only, the items 4 and 5 of the Spanish version of BackPEI received a score of (3) Neither Agree nor Disagree about the first question for experts "Is the Spanish translation of the Portuguese version adequate? Observations". One of the experts informed that: "Construction is confusing in both questions. Sits down (se sienta, in Spanish), means: how many hours the person attend TV 
seated?". In addition, the expert panel suggested to change the courtesy treatment of "usted" for the second person pronoun for the treatment of closeness or familiarity in terms of idiomatic (3rd question of the experts' questionnaire, table 1)

The second-round survey included the changed term "sit down" to "stay" (permanences, in Spanish) and the second person pronoun treatment in all the items. All items in general and item-byitem basis achieved $80 \%$ without exceptions. However, the expert panel suggested more modifications to the items. It was required to change the female gender use in the questionnaire for girls in items 4 and 5 (permaner sentada, in Spanish). It also was suggested modifications for: 14 item "¿cómo sueles llevar la mochila?" (in Spanihs) to keep the pattern of the other questions; 15 and 16 item "¿Cuál es el grado de formación de tu padre/madre/tutora?" (in Sapnish); 19 item include the Spanish pronoun "te ocurre".

In the last round, all the suggestions made in the previous round were incorporated. The expert panel achieved the $100 \%$ of the consensus and scored all the items equal to five, the highest level ( $5=$ Strongly agree) (table 3).

Step 5 (proofreading): No grammatical or spelling errors were found. In the sixth step the prefinal version for the pretest was ready.

Table 3 Results of the assessments of the three Spanish versions of the Back Pain and Body Posture Evaluation Instrument (BackPEI) made by Expert Committee scores using the 5-point Likert scale.

\begin{tabular}{ccccccc}
\hline Domains & \multicolumn{2}{c}{ 1st Round } & \multicolumn{2}{c}{ 2nd Round } & \multicolumn{2}{c}{ 3rd Round } \\
\cline { 2 - 7 } & $\mathrm{X}$ & $\mathrm{SD}$ & $\mathrm{X}$ & $\mathrm{SD}$ & $\mathrm{X}$ & $\mathrm{SD}$ \\
$\begin{array}{c}\text { Semantic- } \\
\text { translation }\end{array}$ & 4.81 & .269 & 4.83 & .236 & 5.00 & - \\
$\begin{array}{c}\text { Conceptual } \\
\text { and }\end{array}$ & & & & & & \\
$\begin{array}{c}\text { understanding } \\
\text { Idiomatic }\end{array}$ & 4.93 & .101 & 5.00 & - & 5.00 & - \\
Experiential & 5.00 & .707 & 5.00 & - & 5.00 & - \\
\hline $\mathrm{X}=$ mean; SD $=$ standard deviation. & & & & & \\
\end{tabular}

\subsection{Test- retest Reliability}

To test its reliability, the Spanish prefinal version of the BackPEI was applied to 224 adolescents twice (test-retest), within a seven-day interval. According to the kappa coefficient for questions 1-20 in the questionnaire, 5 were classified as "very good", 8 as "good", 1 as "moderate" and 1 as "fair" (table 4). The response rate was high, with losses of less than $10 \%$. According to question $21(n=115)$, the intensity of the pain did not show differences between the averages for the test $(=4.72 \pm S D=$ 2.33 ) and re-test $(=4.58 \pm S D=2.37)(p=.333)$, and the responses for these two tests were highly correlated (ICC $=.951,95 \%$ IC: . $928-.966 ; \mathrm{p}=.0001)$.

Table 4 Results of the kappa coefficient for the 20 questions in the Spanish version of Back Pain and Body Posture Evaluation Instrument for adolescents (Spanish BackPEI).

\begin{tabular}{ccccc}
\hline $\mathbf{Q}$ & Description of question & $\begin{array}{c}\text { n (missing } \\
\text { data) }\end{array}$ & A & $\begin{array}{c}\text { k value } \\
(\text { IC 95 \%) }\end{array}$ \\
\hline 1 & Practice of physical exercise & $224(0.0 \%)$ & $96.9 \%$ & $\begin{array}{c}.918 \\
(-.031-, 060)\end{array}$ \\
\hline 2 & Frequency of physical exercise & $223(0.4 \%)$ & $87.8 \%$ & $\begin{array}{c}.834 \\
(-, 034-, 060)\end{array}$ \\
\hline 3 & Competitive or non-competitive physical & $224(0.0 \%)$ & $93.3 \%$ & $\begin{array}{c}.897 \\
(-, 028-, 052)\end{array}$ \\
\hline 4 & $\begin{array}{c}.522 \\
\text { exercise }\end{array}$ & $224(0.0 \%)$ & $68.8 \%$ & $\begin{array}{c}.529-, 096) \\
(-, 069)\end{array}$
\end{tabular}




\begin{tabular}{|c|c|c|c|c|}
\hline 5 & Time spent each day using a computer & $224(0.0 \%)$ & $78.6 \%$ & $\begin{array}{c}.583 \\
(-, 096-, 101)\end{array}$ \\
\hline 6 & Reading and/or studying in bed & $224(0.0 \%)$ & $67.4 \%$ & $\begin{array}{c}.669 \\
(-, 054-, 084)\end{array}$ \\
\hline 7 & Preferred sleeping position & $216(3.6 \%)$ & $89.8 \%$ & $\begin{array}{c}.827 \\
(-, 039-, 068)\end{array}$ \\
\hline 8 & Time slept each night & $222(0.9 \%)$ & $66.7 \%$ & $\begin{array}{c}.651 \\
(-, 052-, 080)\end{array}$ \\
\hline 9 & Sitting position when writing & $224(0.0 \%)$ & $86.6 \%$ & $\begin{array}{c}.312 \\
(-, 152-, 189)\end{array}$ \\
\hline 10 & Sitting position on a chair when talking & $224(0.0 \%)$ & $86.2 \%$ & $\begin{array}{c}.378 \\
(-, 141-, 182)\end{array}$ \\
\hline 11 & Sitting position when using a computer & $224(0.0 \%)$ & $88.4 \%$ & $\begin{array}{c}.550 \\
(-, 110-, 159)\end{array}$ \\
\hline 12 & $\begin{array}{l}\text { Position adopted when lifting an object from the } \\
\text { floor }\end{array}$ & $224(0.0 \%)$ & $92 \%$ & $\begin{array}{c}.762 \\
(-, 062-, 105)\end{array}$ \\
\hline 13 & Carrying school material & $224(0.0 \%)$ & $100 \%$ & $1.000(-)$ \\
\hline 14 & Mode of transporting the school backpack & $224(0.0 \%)$ & $98.6 \%$ & $\begin{array}{c}.762 \\
(-, 135-, 234)\end{array}$ \\
\hline 15 & Mother's level of education & $223(0.4 \%)$ & $78.8 \%$ & $\begin{array}{c}.729 \\
(-, 043-, 070)\end{array}$ \\
\hline 16 & Father's level of education & $224(0.0 \%)$ & $79.8 \%$ & $\begin{array}{c}.743 \\
(-, 041-, 068)\end{array}$ \\
\hline 17 & Parents with a history of back pain & $224(0.0 \%)$ & $79.9 \%$ & $\begin{array}{c}.689 \\
(-, 052-, 082)\end{array}$ \\
\hline 18 & Presence of back pain & $224(0.0 \%)$ & $88.8 \%$ & $\begin{array}{c}.792 \\
(-, 043-, 074)\end{array}$ \\
\hline 19 & Frequency of back pain a & $118(0.0 \%)$ & $61.1 \%$ & $\begin{array}{c}.528 \\
(-, 077-, 109)\end{array}$ \\
\hline 20 & Impeding the performance of activities a & $107(9.3 \%)$ & $76.6 \%$ & $\begin{array}{c}.517 \\
(-, 110-, 155) \\
\end{array}$ \\
\hline
\end{tabular}

$\mathrm{Q}=$ questions; $\mathrm{A}=$ Agreeement; $\mathrm{k}=$ Cohen's kappa coefficient $(\mathrm{k})$

a Refers to those who answered 'yes' in question $18(\mathrm{n}=118)$

\section{Discussion}

The overarching objective of this study was to translate and validate a Spanish-language adaptation of the BackPEI for adolescents. Currently, the literature lacks valid and reliable instruments designed to assess the postural habits.

To our knowledge, only two questionnaires have been validated according this content $(15,16)$. However, the BackPEI not only evaluate the postural habits adopted by school-age children during activities of daily life (ADLs), but also the possible risk factors associated with this condition, such as the prevalence of BP. This allows it to be considered as a comprehensive instrument that considers both dependent, independent and confounding variables in just 21 questions and five categories: a) practice physical exercise $(n=3)$; b) active lifestyle $(n=5)$; c) postural habits $(n=6)$ of which sitting postures $(n=3)$, lifting weight $(n=1)$ and using backpacks $(n=2)$; $)$ parent studies $(n=2)$ and e) epidemiological $(n=5)$. Moreover, the BackPEI stands out from others because it was developed with separate versions for boys and girls and because it has been translated into English, which facilitates access to its content by other researchers, although the reproducibility of the English version has not been assessed yet. Besides, as the studies suggest (18), to be able to use the BackPEI in English it would have to follow a complete process of translation and cross-cultural adaptation.

On the other hand, the BEHALVES (16) differs from this by focusing on the deep assessment of postural habits in ADLs. The 30 questions about habits were divided into five categories: a) Standing 
Posture ( $(n=4), b)$ Sitting Posture $(n=9), c)$ Using backpacks $(n=7), d)$ Mobilizing heavy weights $(n=$ $5)$ and e) Lying Posture $(n=5)$. This means that this questionnaire delves further into the study.

According to the guideless $(18,19)$, the process of the translation and cross-cultural adaptation of the Spanish BackPEI version followed the recommendations proposed. Regarding to the reliability and reproducibility the Cohen's kappa coefficient for questions 1-20 in the questionnaire, were classified well (table 4). Specifically, the three questions on sitting position obtained the lowest coefficients, coinciding with the original version of the BackPEI (15) and the Turkish version (25). However, in the target version the results were less than .4 in items 9 and 10, but they got a high agreement $(86 \%)$. In the three versions of the BackPEI the lowest score was reached by the item 9 . This result could be due to the fact that the type of response was multiple choice but the result was dichotomous. Having more than two options makes the rate of agreement vary more. On the other hand, sitting position changes every 46 seconds (26). Throughout the school day as well as the day we adopt many proper positions and therefore could be various responses affecting agreement. Some research suggests that people with LBP assume more static, sustained end-range postures while sitting, and use large infrequent shifts in posture rather than small, subtle spinal movements regularly $(27,28)$. As a result, dynamic sitting approaches which facilitate subtle spinal motion have been proposed as a means of reducing LBP during sitting (29). The question 21 about the intensity of the pain did not show differences between the averages for the test and re-test, and similar and high correlated were find in the both tests (ICC > 0.93; $\mathrm{p}=0.05$ ).

Concerning populations, the two translated versions, the Turkish and the Spanish, were applied to a sample of secondary school students. About the test-retest interval, in the original and Spanish versions were administered twice within a seven-day interval during, while in the Turkish version they used two weeks' interval. One week may be considered sufficient time for students forget the answers they gave in the previous week, however insufficient for changing their daily habits (24). Differently, in the Turkish BackPEI version the authors used the Cohen's kappa coefficient for question 21 (categorical variable) instead of the Wilcoxon test, what confuse the readers.

In order to continue improving evaluation tools for assessing back health in school setting, the validity of an instrument is analyzed through content validity, criterion validity and construct validity (17). Criterion validity refers to the degree to which the instrument produces results similar to those of other existing and valid instruments/equipment (Gold Standard) to evaluate the same construct (30). Thus, criterion validity is the only test that both the BackPEI and the BEHALVES need to pass. And now, because they are available as a valid and reliable tool in the Spanish language for an adolescent population, criterion validity could be analysed. Besides, by age, perhaps the BackPEI could be used as a Gold Standard and the results between the two tools could be compared.

On the subject of the implications for teachers and school health, it is important to have questionnaires as tools for assessing postural habits but even risk factors in children and adolescents in school setting. Also, the BackPEI is a quick and effective instrument to screen, students only need 10-20 minutes to complete. And in the case of wanting to complete the information on the daily postural habits, the BEHALVES can be applied and deepen in the case studies.

\subsection{Limitations}

Since the panel size was neither representative of any population nor statistically calculated, and recruiting of the experts was a subjective process, our results should not be interpreted as representing the views of all the experts of the studied fields. The number and specialty of the translator could be improved. Moreover, it could be developed pilot testing of the prefinal version of the instrument in the target language with a monolingual sample and another with a bilingual sample.

\section{Conclusions}

Psychometric testing indicated that the Spanish version of the BackPEI provided valid and reliable scores that were similar to the results obtained with the original Brazilian version. The 
Spanish BackPEI version represents a successful instrument for evaluating adolescent's back pain and body postural at school.

Supplementary Materials: The following are available online at www.mdpi.com/xxx/s1, Figure S1: title, Table S1: title, Video S1: title.

Author Contributions: “Conceptualization, Miñana-Signes, Monfort-Pañego and Noll; methodology, MiñanaSignes, Monfort-Pañego and Noll; software, Miñana-Signes, Monfort-Pañego, Morant and Noll; validation, all the authors; formal analysis, all the authors; data curation, Morant; writing - original draft preparation, MiñanaSignes and Morant; writing-review and editing, all the authors; visualization, Monfort-Pañego and Noll; supervision, Monfort-Pañego and Noll; project administration, Miñana-Signes. All authors have read and agreed to the published version of the manuscript.".

Funding: "This research received no external funding"

Acknowledgments: The secondary school and PETE who agreed to participate in this study. To the experts who participated in the Delphi-process. The people who helped us with the translation of the different versions.

Conflicts of Interest: “The authors declare no conflict of interest."

\section{References}

1. Wu A, March L, Zheng X, Huang J, Wang X, Zhao J, et al. Global low back pain prevalence and years lived with disability from 1990 to 2017: estimates from the Global Burden of Disease Study 2017. Annals of Translational Medicine. 2020;8(6).

2. Dissing KB, Hestbæk L, Hartvigsen J, Williams C, Kamper S, Boyle E, et al. Spinal pain in Danish school children-how often and how long? The CHAMPS Study-DK. BMC musculoskeletal disorders. 2017;18(1):67.

3. Maher C, Underwood M, Buchbinder R. Non-specific low back pain. The Lancet. 2017;389(10070):736-47.

4. O'Sullivan K, O'Keeffe M, Forster BB, Qamar SR, van der Westhuizen A, O'Sullivan PB. Managing low back pain in active adolescents. Best Practice \& Research Clinical Rheumatology. 2019;33(1):102-21.

5. Noll M, Candotti CT, Rosa BNd, Vieira A, Loss JF. Back pain and its risk factors in Brazilian adolescents: a longitudinal study. British Journal of Pain. 2019:2049463719871751.

6. Alibegović A, Mačak Hadžiomerović A, Pašalić A, Domljan D. School Furniture Ergonomics in Prevention of Pupils' Poor Sitting Posture. Drvna industrija: Znanstveni časopis za pitanja drvne tehnologije. 2020;71(1):88-99.

7. Leboeuf-Yde C, Kyvik KO. At what age does low back pain become a common problem? A study of 29,424 individuals aged 12-41 years. Spine (Phila Pa 1976). 1998 Jan 15;23(2):228-34.

8. Korovessis P, Koureas G, Papazisis Z. Correlation between backpack weight and way of carrying, sagittal and frontal spinal curvatures, athletic activity, and dorsal and low back pain in schoolchildren and adolescents. J Spinal Disord Tech. 2004 Feb;17(1):33-40.

9. Sato T. Bone and joint diseases in children. Low back pain in children. Clin Calcium. 2010 Jun;20(6):887-95.

10. Hestbaek L, Leboeuf-Yde C, Kyvik KO. Are lifestyle-factors in adolescence predictors for adult low back pain? A cross-sectional and prospective study of young twins. BMC Musculoskelet Disord. 2006 Mar $15 ; 7: 27$.

11. Bettany-Saltikov J, Kandasamy G, Van Schaik P, McSherry R, Hogg J, Whittaker V, et al. School-based education programmes for improving knowledge of back health, ergonomics and postural behaviour of school children aged 4-18: A systematic review. Campbell Systematic Reviews. 2019;15(1-2):1-11.

12. Michaleff ZA, Kamper SJ, Maher CG, Evans R, Broderick C, Henschke N. Low back pain in children and adolescents: a systematic review and meta-analysis evaluating the effectiveness of conservative interventions. Eur Spine J. 2014 Oct;23(10):2046-58.

13. Miñana-Signes V, Monfort-Pañego M, Rosaleny-Maiques S. Improvement of knowledge and postural habits after an educational intervention program in school students. Journal of Human Sport and Exercise. 2019;14(1).

14. Dugan JE. Teaching the body: a systematic review of posture interventions in primary schools. Educational Review. 2018;70(5):643-61. 
15. Noll M, Candotti CT, Vieira A, Loss JF. Back pain and body posture evaluation instrument (BackPEI): development, content validation and reproducibility. International Journal of Public Health. 2013;58(4):565-72.

16. Monfort-Pañego M, Miñana-Signes V. Psychometric Study and Content Validity of a Questionnaire to Assess Back-Health-Related Postural Habits in Daily Activities. Measurement in Physical Education and Exercise Science. 2020:1-10.

17. Polit DF. Assessing measurement in health: Beyond reliability and validity. Int J Nurs Stud. 2015;52(11):1746-53.

18. Sousa VD, Rojjanasrirat W. Translation, adaptation and validation of instruments or scales for use in crosscultural health care research: a clear and user-friendly guideline. J Eval Clin Pract. 2011;17(2):268-74.

19. Beaton DE, Bombardier C, Guillemin F, Ferraz MB. Guidelines for the process of cross-cultural adaptation of self-report measures. Spine. 2000;25(24):3186-91.

20. Epstein J, Osborne RH, Elsworth GR, Beaton DE, Guillemin F. Cross-cultural adaptation of the Health Education Impact Questionnaire: experimental study showed expert committee, not back-translation, added value. J Clin Epidemiol. 2015;68(4):360-9.

21. Likert R. A technique for the measurement of attitudes. Archives of Psychology. 1932;22 140:55.

22. Stull DE, Leidy NK, Parasuraman B, Chassany O. Optimal recall periods for patient-reported outcomes: challenges and potential solutions. Curr Med Res Opin. 2009;25(4):929-42.

23. Schlademann S, Meyer T, Raspe H. The test-retest reliability of a questionnaire on the occurrence and severity of back pain in a German population sample. International journal of public health. 2008;53(2):96103.

24. Staes F, Stappaerts K, Vertommen H, Everaert D, Coppieters M. Reproducibility of a survey questionnaire for the investigation of low back problems in adolescents. Acta Paediatrica. 1999;88(11):1269-73.

25. Gençbaş D, Bebiş $H$. The validity and reliability of the Turkish version of Back Pain and Body Posture Evaluation Instrument (BACKPEI). Acıbadem Üniversitesi Sağlık Bilimleri Dergisi. 2019;10(3).

26. Cardon G, De Clercq D, De Bourdeaudhuij I, Breithecker D. Sitting habits in elementary schoolchildren: a traditional versus a "Moving school". Patient Educ Couns. 2004 Aug;54(2):133-42.

27. Dankaerts W, O'Sullivan P, Burnett A, Straker L. Differences in sitting postures are associated with nonspecific chronic low back pain disorders when patients are subclassified. Spine. 2006;31(6):698-704.

28. Vergara M, Page Á. Relationship between comfort and back posture and mobility in sitting-posture. Appl Ergon. 2002;33(1):1-8.

29. Van Dieën J, De Looze MP, Hermans V. Effects of dynamic office chairs on trunk kinematics, trunk extensor EMG and spinal shrinkage. Ergonomics. 2001;44(7):739-50.

30. Mokkink LB, Terwee CB, Patrick DL, Alonso J, Stratford PW, Knol DL, et al. The COSMIN study reached international consensus on taxonomy, terminology, and definitions of measurement properties for healthrelated patient-reported outcomes. J Clin Epidemiol. 2010;63(7):737-45. 